\title{
Congenital Cyst and Fistula of the Dorsum of the Nose: A Case Report and Literature Review
}

\author{
O. Benhoummad, F. E. Rizkou, S. Salhi, Y. Rochdi, and A. Raji
}

\section{ABSTRACT}

Congenital cyst and fistula of the dorsum of the nose is a rare congenital entity. We report a new case of dorsum nasal fistula in a 5 year old male patient that communicates the frontal region with the subcutaneous surface. Radiologic imaging showed a median $5 \mathrm{~mm}$ defect, in the projection of the metopic suture that leads to a communication between the frontal region and the skin figure. Complete resection was performed by an external approach with vertical incision of the cyst. The histological diagnosis was consistent with a dermoid fistulized cyst. The follow-up displayed unremarkable finding, the patient did not present any diplopia nor decreased visual acuity, or any signs of meningitis or cerebrospinal fluid rhinorrhoea, or saddle nose.

Keywords: Congenital cyst, dorsum of the nose, midline fistula.

Submitted: August 5, 2021

Published: September 13, 2021

ISSN: 2593-8339

DOI: $10.24018 /$ ejmed.2021.3.5.1001

\section{O. Benhoummad *}

ENT and Neck and Head surgery department, university hospital of Agadir. Faculty of Medicine and Pharmacy of Agadir, Morocco.

(e-mail: benhoummadorl@gmail.com)

F. E. Rizkou

ENT and Neck and Head surgery

department, University Hospital of

Marrakech, Morocco.

(e-mail: fati94rizkou@gmail.com)

S. Salhi

ENT and Neck and Head surgery

department, University Hospital of

Marrakech, Morocco.

(e-mail: salma.salhi@edu.uca.ma)

Y. Rochdi

ENT and Neck and Head surgery

department, University Hospital of

Marrakech, Morocco.

(e-mail: rochdi_86@hotmail.com)

A. Raji

ENT and Neck and Head surgery

department, University Hospital of

Marrakech, Morocco.

(e-mail: raji.abdelaziz@gmail.com)

*Corresponding Author

\section{INTRODUCTION}

Midline fistula of nasal dorsum is deemed a rare congenital anomaly, most often sporadic. Their intracranial expansion is a source of potential complications, such as meningitis, intracranial abscesses thus the urgency of an early surgical correction [1].

We document a new case of dorsum nasal fistula in a 5 years old male enfant that communicates the frontal region with the subcutaneous surface.

\section{CASE REPORT}

A 5 years old male enfant, without a forego pathological history, suffered since birth, from a gradually increasing swelling in the nasal dorsum fistulized to the skin without any discharged materials, with no other associated lesions or signs nor any malformation and no prior or recurrent infections were observed or described by the parent's patient.

The clinical examination displays a firm, slightly painful and well-outlined cyst in the dorsum nasal with the fistula opening Fig. 1, without any cervical adenopathy. The ophthalmologic and neurologic examinations were unremarkable. Endoscopic examination of both nasal cavities appeared normal.

CT scan showed a median $5 \mathrm{~mm}$ defect, in the projection of the metopic suture that leads to a communication between the frontal region and the skin Fig. 2.

The chirurgical intervention relied on the external approach with vertical incision of the cyst followed by its dissection and complete resection Fig. 3.

Indeed, the histological study of the cyst did substantiate the diagnosis revealing a dermoid fistulized cyst.

The follow-up was undistinguished, so as the patient did 
not sport any diplopia, decreased visual acuity, nor cerebrospinal fluid rhinorrhoea or signs of meningitis, or saddle nose.

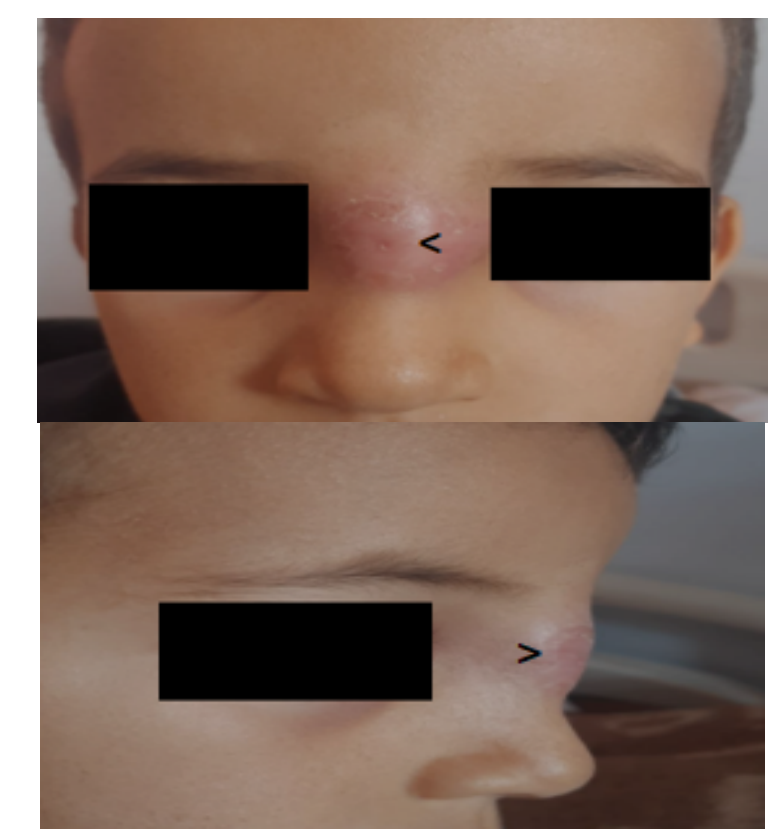

Fig. 1. Fistulized cyst and pit (arrowhead) in the upper one third of the nasal dorsum.

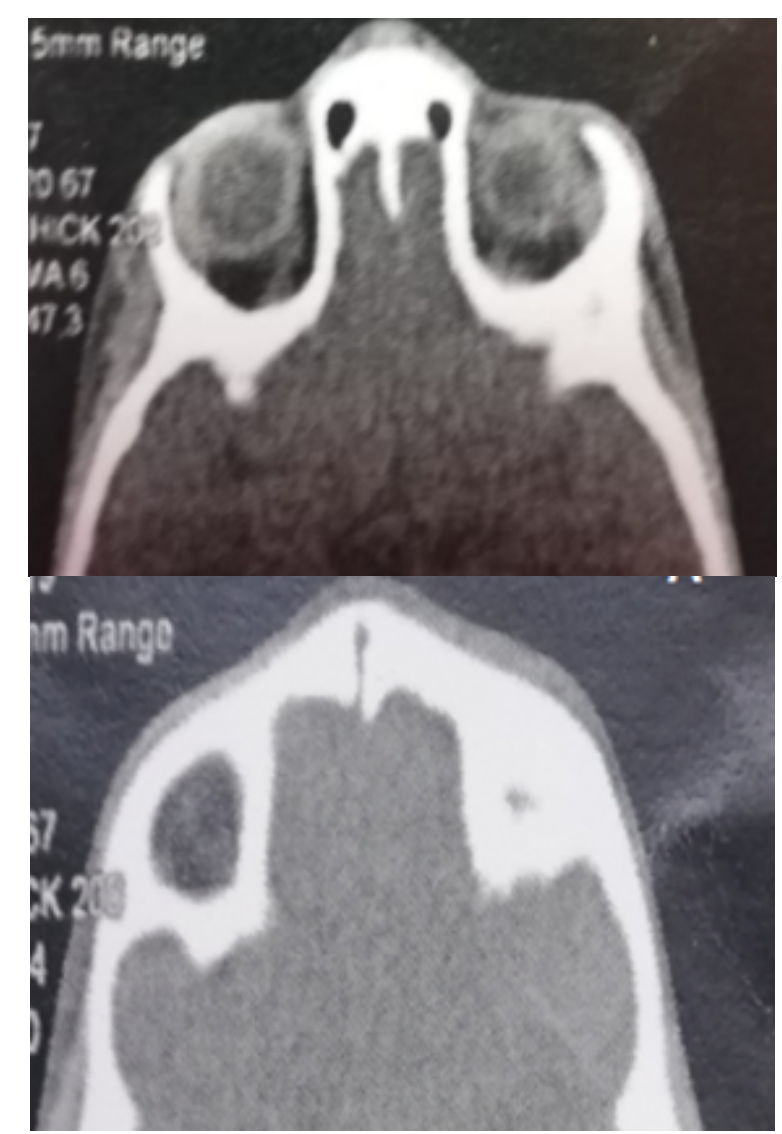

Fig. 2. Axial CT scan demonstrating a midline defect in the projection of the metopic suture.

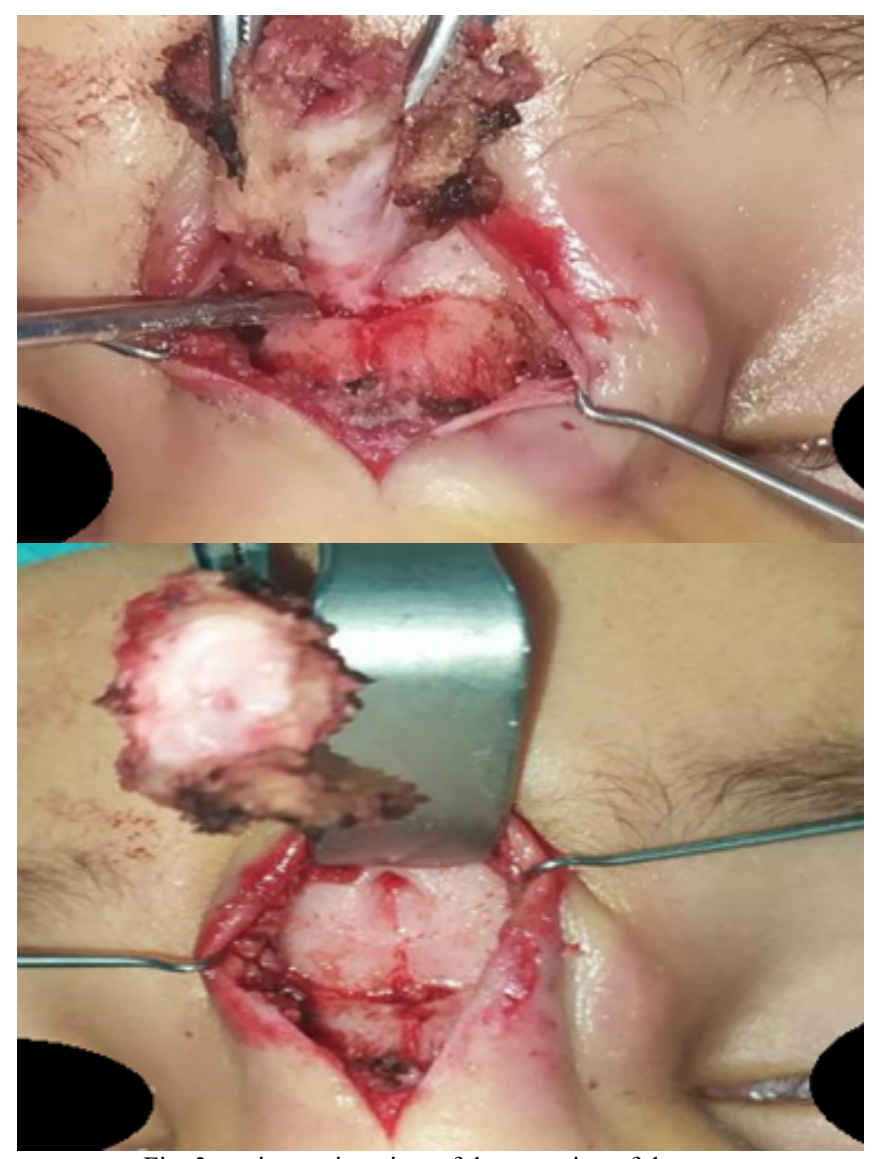

Fig. 3. perioperative view of the resection of the cyst.

\section{DISCUSSION}

Congenital midline lesions of the nose are aberrated congenital abnormalities occur once in every 20000 to 40000 births, of these; nasal dermoid sinus cysts (NDSCs) are one of the most frequently encountered lesions [1], [2]. they appear either at birth or in the early infancy and most frequently sporadically with male predominance, nevertheless some rare familial cases were reported [3], [4].

The most accepted theory is that of Pratt [2], itself emerge from the work of Grunwald [13]. This theory states that NDSC is the result of incomplete regression of the diverticula of dura; (with or without arachnoid and neural tissue); that is formed up to the end of the second month. The diverticula projects anteriorly through the fonticulus frontalis and/or inferiorly from the skull base to the nasal tip defining the prenasal space, the latter is delineated by the cartilaginous nasal capsule and the membranous ossification centers of the nasal bones, witch overall leads to an ectodermal residue persisting in either the prenasal or nasofrontal region that extends from the foramen caecum to the tip of the nose [2], [11]-[14].

Although the pathognomonic display of NDSCs is hair protruding through a punctum, many clinical presentations can be found, the most communally is a midline mass, mainly in the nasal dorsum, but also from the glabella to the nasal tip [2], they may be associated with sinus opening with or without discharge of sebaceous materiel [5], [6]. The intermittent leak of cerebrospinal fluid may also be noted [12]. Complications may lead to NDCS's diagnosis, such as recurrent infection, cerebral abscess, thrombosis of the cavernous sinus, meningitis and periorbital cellulitis and 
most importantly are due to intracranial extension, mainly extradural, however Intradural extensions have been described [3], [5], [7], [8].

Associated malformative anomalies; that mainly concern the face, the brain and the first branchial arch, with no specific syndrome were observed, such as aural atresia, hydrocephalus, pharyngeal arch sinus, deformity of the pinna, craniosynostosis mental retardation and so on [3], [4]. Wardinsky et al. [8] reported the higher frequency of intracranial extensions in event of multiple malformations $(65 \%)$ in contrast to isolated NDSC (31\%). Paller et al. [10] noted that the Columellar localization is in fact associated with lesser risk of intracranial expansion. Elsewhere, Bradley [11] believed that the locations of dermal manifestations gave no indication of loftier prolongations.

The main differential diagnosis rest in nasal glioma, encephaloceles, mucocele, osteomyelitis of the frontal bone and traumatic deformity and should always be searched [2], [3].

The large radius of differential diagnosis and the possibility of intracranial extension compel the rigorous preoperative radiographic examination. CT and MRI; the gold standard of now a day, can adequately and effectively delineate bony anatomy and soft tissue. The previous detail is provided by axial and coronal Computed tomography especially of the anterior or central skull base. Imaging should include the entire nasal, ethmoid, and orbital region from the tip of the nose through the anterior cranial fossa. Coronal images should extend posterior to the crista galli. Contrast enhanced images are very much recommended to differentiate enhancing cartilage from a defect in skull base and to set apart enhancing nasal mucosa from nonenhancing dermoids. MRI in the other hand, allows to highlight the fistulous path (multiplanar reconstruction), distinguish bone, cartilage, cerebral parenchyma, cerebrospinal fluid, epidermoid lesion (diffusion imaging). It is superior to CT scans for studying soft tissue. The use of contrast also differentiates the non-enhancing dermoids and other enhancing masses such as hemangioma or teratoma. It is prominent to recognize that in infants, the crista galli is unossified with no marrow fat, thus, a hyper-intensity T1weighted images in the environs of the crista galli in the new born should suggest the presence of intracranial dermoid but could also add to the false-positive findings of intracranial extension [3], [5], [12], [15]-[17].

There are certified criteria for intracranial extension, it entails bifidity of the crista galli process and enlargement of the foramen caecum, that are encountered in all dermoid cysts. If absent, these criteria are conclusive only, therefor excluding an upper intracranial extension. Whereas their presence is only suggestive of such expansion [3], [15], [18]-[20].

In terms of therapeutic management, the indications lie on the prevention of infection, bone destruction and expansion of the lesion. All references agree that a complete excision of the lesions is a must, regardless of the extension. Different approaches have been proposed, ranging from a simple extracranial excision to complex procedures combining intracranial excision and nasal reconstruction. Drainage, curettage, aspiration, incision, and subtotal excision and so on, fail to obliterate the cyst with a recurrence rate grading from $30 \%$ to $100 \%$ [5], [22], [23].

An assortment of routes exists, all the same the standard midline vertical incision remains the most common one. Posnick et al. [17] and Kelly et al. [25] reported better cosmetic outcomes with the midline vertical incision compared to the horizontal and inverted- $U$ ones. Bradley [11] however, reported $37 \%$ poor aesthetic results, and Denoyelle et al. [3] reported $60 \%$ widening of scar associated with vertical incisions. Other paths, such as lateral rhinotomy, degloving procedures, inverted-U incision, transverse incision external and rhinoplasty have also been propped [5], [16], [17]-[22]. The ensuing approach have been promoted by many authors as the preferred method for extracranial removal [16], [17], [24]. If the sinus tract extends deep to the nasal bones, with a recommendation of nasal osteotomy to insure a good exposure [5].

Histopathologic examination discloses a well-defined cyst lined by squamous epithelial of ectodermal origin's, the presence or not of a mature epidermal appendage; especially sebaceous glands and hair follicles; allows us to distinguish dermoid and epidermoid cysts; as the later lack any adnexal structures [3], [5], [6].

\section{CONCLUSION}

The NDSCs are an uncommon birth defect, sometimes may be discreet, other times with potential complications that justify their early surgical management. CT and eventually MRI should be performed to detect any intracranial mass.

\section{REFERENCES}

[1] S. A. Paller, J.M. Pensler, T. Tomita, "Nasal Midline Masses in Infants and Children Dermoids, Encephaloceles, and Gliomas," Arch Dermatol, 1991;127:362-366.

[2] L.W. Pratt, "Midline cyst of the nasal dorsum: embryologic origin and treatment," Laryngoscope, 1985;75:968-75.

[3] F. Denoyelle, V. Ducroz, G. Roger, E.N. Garabedian, "Nasal Dermoid Sinus Cysts in Children," The American Laryngological, Rhinological and Otological society, Inc; Laryngoscope, 107:795$800,1997$.

[4] M.A. Khan, A.G. Gibb, "Median dermoid cyst of the nose: familial occurrence," J Laryngol Oto, 1970;84:709-15. 10.

[5] R. Rahbar, P. Shah, J.B. Mulliken, et al, "The presentation and management of nasal dermoid: a 30-year experience," Arch Otolaryngol Head Neck Surg 2003 Apr, 129(4):464-71.

[6] O. Kleina, E. Simonb, L. Coffinet, A. Jouda, C. Ghetemmea, J.C. Marchal, "Nasal dermal sinus in children: A review based on a series of 6 cases," Neurochirurgie, Vol. 60, Issue 12, February-April 2014, pp. 27-32.

[7] T. Wardinsky, R. Pagon, R. Kropp, P. Hayden, S. Clmn, "Nasal dermoid sinus cyst association with intracranial extension and multiple malformations," Cleft Palate Craniofac J, 1991;28:87-95SA.

[8] J.P. Uglietta, O.B. Boyko, D.J. Rippe, "Intracerebral extension of nasal dermoid cyst: CT appearance," J Comput Assist Tomogr, 1989; 13: 1061-4.

[9] G. Cotin, F. Leperchey, E.N. Garabedian, "Fistules congenitales medianes du dos du nez: etude embryologique, clinique et therapeutique," Ann Pediatrie, 1984;3 1:945-9. 14.

[10] J. Barkovich, P. Vandermarck, M. Edwards, P.H. Cogen., "Congenital nasal masses: CT and MR imaging features in 16 cases," AJNR Am J Neuroradiol, 1991;12:105-16.

[11] P.J. Bradley, S.D. Singh, "Congenital nasal masses: diagnosis and management," Clin Otolaryngol, 1982;7:87-97. 26.

[12] W.E. Blake, C.W. Chow, A.D. Holmes, J.G. Meara, "Nasal dermoid sinus cysts: a retrospective review and discussion of investigation and management," Ann Plast Surg, 2006;57:535-40. 
[13] L. Grünwald, "Beiträge sur Kenntnis kongenitaler Geschwülste und Missbildungen an Ohr und Nase," Zstchr F Ohrenh, 1910;60:270-80.

[14] J.B. Charrier, I. Rouillon, G. Roger, F. Denoyelle, P. Josset, E.N. Garabedian, "Craniofacial dermoids: an embryological theory unifying nasal dermoid sinus cysts," Cleft Palate Craniofac J, 2005;42(1):51-7.

[15] J. Pensler, B. Bauer, T. Naidich, "Craniofacial dermoids," Plast Reconstr Surg, 1988;82:953-8.

[16] J.C. Posnick, P. Bortoluzzi, D.C. Armstrong, J.M. Drake, "Intracranial nasal dermoid sinus cysts: computed tomographic scan findings and surgical results," Plast Reconstr Surg, 1994;32:745-54.

[17] F. Lindbichler, H. Braun, J. Raith, G. Ranner, C. Kugler, M. Uggowitzer, "Nasal dermoid cyst with a sinus tract extending to the frontal dura mater: MRI.," Neuroradiology, 1997;39(7):529-31.

[18] H.M. Brownstein, S. Lewis, S. Raymond, "Fistula of the Dorsum of the Nose," Arch Dermatol, Vol 109. Feb 1974.

[19] R. Yavuzer, U. Bier, I.T. Jackson, "Be careful: it might be a nasal dermoid cyst," Plast Reconstr Surg, 1999 Jun;103(7):2082-3.

[20] P. Vibe, E. Lontoft, "Congenital Nasal Dermoid Cysts and Fistulas: Case Reports," Scandinavian Journal of Plastic and Reconstructive Surgery, volume 19,1985 issue 1 .

[21] R.J. Rohrich, J.B. Lowe, M.R. Schwartz, "The role of open rhinoplasty in the management of nasal dermoid cysts," Plast Reconstr Surg, 1999 Oct;104(5):1459-66; quiz 1467; discussion 1468.

[22] J.H. Kelly, M. Strome, B. Hall, "Surgical update on nasal dermoids," Arch Otolaryngol, 1982 Apr;108(4):239-42. 